\title{
Perceived spatial stigma, body mass index and blood pressure: a global positioning system study among low-income housing residents in New York City
}

\author{
Dustin T. Duncan, ${ }^{1-4}$ Ryan R. Ruff, ${ }^{2,5}$ Basile Chaix, ${ }^{6,7}$ Seann D. Regan, ${ }^{1}$ James H. Williams, ${ }^{1}$ \\ Joseph Ravenell, ${ }^{1}$ Marie A. Bragg, ${ }^{1,2}$ Gbenga Ogedegbe, ${ }^{1,2}$ Brian Elbel ${ }^{1-3,8}$ \\ ${ }^{1}$ Department of Population Health, New York University School of Medicine, New York, NY; \\ ${ }^{2}$ College of Global Public Health, New York University, New York, NY; ${ }^{3}$ Population Center, New \\ York University, New York, NY; ${ }^{4}$ Center for Data Science, New York University, New York, NY; \\ ${ }^{5}$ Department of Epidemiology and Health Promotion, New York University College of \\ Dentistry, New York, NY, USA; ' ${ }^{6}$ Pierre et Marie Curie University, Pierre Louis Institute of \\ Epidemiology and Public Health, Paris; ${ }^{7}$ National Institute of Health and Medical Research, \\ Pierre Louis Institute of Epidemiology and Public Health, Paris, France; ${ }^{8}$ Wagner Graduate \\ School of Public Service, New York University, New York, NY, USA
}

\author{
Correspondence: Dustin T. Duncan, Spatial Epidemiology Lab, Department \\ of Population Health, New York University School of Medicine, 227 East 30th \\ street, 6th Floor, Room 621, New York, NY 10016, USA. \\ Tel: +1.646.5012674. Fax: +1.646.5012706. \\ E-mail: Dustin.Duncan@nyumc.org
}

Key words: Spatial stigma; Spatial epidemiology; Global positioning system technology; Low-income housing residents; Cardiovascular disease.

Acknowledgements: the NYC Low-income Housing, Neighborhoods and Health Study was supported by the NYU-HHC Clinical and Translational Science Institute (CTSI) Pilot Project Awards Program (Dr. Dustin Duncan, Principal Investigator). The NYU-HHC CTSI is supported in part by grant UL1TR000038 (Dr. Bruce Cronstein, Principal Investigator and Dr. Judith Hochman, co-Principal Investigator) from the National Center for Advancing Translational Sciences of the National Institutes of Health. We thank the research assistants for this project: Maliyhah Al-Bayan; Shilpa Dutta; William Goedel; Brittany Gozlan; Kenneth Pass; James Williams; and Abebayehu Yilma. We thank Jeff Blossom for geocoding the participants' addresses, calculating neighborhood percent non-Hispanic Black and neighborhood median household income in ArcGIS and creating the figure used in this study, and we thank William Goedel, Samantha Bennett and Jermaine Blakley for their assistance with the preparation of this manuscript. We also thank the participants for engaging in this research.

Received for publication: 17 July 2015.

Revision received: 29 January 2016.

Accepted for publication: 1 February 2016.

CC Copyright D.T. Duncan et al., 2016

Licensee PAGEPress, Italy

Geospatial Health 2016; 11:399

doi:10.4081/gh.2016.399

This article is distributed under the terms of the Creative Commons Attribution Noncommercial License (CC BY-NC 4.0) which permits any noncommercial use, distribution, and reproduction in any medium, provided the original author(s) and source are credited.

\begin{abstract}
Previous research has highlighted the salience of spatial stigma on the lives of low-income residents, but has been theoretical in nature and/or has predominantly utilised qualitative methods with limited generalisability and ability to draw associations between spatial stigma and measured cardiovascular health outcomes. The primary objective of this study was to evaluate relationships between perceived spatial stigma, body mass index (BMI), and blood pressure among a sample of low-income housing residents in New York City (NYC). Data come from the community-based NYC Low-income Housing, Neighborhoods and Health Study. We completed a crosssectional analysis with survey data, which included the four items on spatial stigma, as well objectively measured BMI and blood pressure data (analytic $n=116 ; 96.7 \%$ of the total sample). Global positioning systems (GPS) tracking of the sample was conducted for a week. In multivariable models (controlling for individual-level age, gender, race/ethnicity, education level, employment status, total household income, neighborhood percent non-Hispanic Black and neighborhood median household income) we found that participants who reported living in an area with a bad neighborhood reputation had higher $\mathrm{BMI}(\mathrm{B}=4.2,95 \% \mathrm{CI}$ : $-0.01,8.3, \mathrm{P}=0.051)$, as well as higher systolic blood pressure $(\mathrm{B}=13.2,95 \% \mathrm{CI}$ : $3.2,23.1, \mathrm{P}=0.01)$ and diastolic blood pressure $(\mathrm{B}=8.5,95 \% \mathrm{CI}: 2.8,14.3, \mathrm{P}=0.004)$. In addition, participants who reported living in an area with a bad neighborhood reputation had increased risk of obesity/overweight [relative risk $(\mathrm{RR})=1.32,95 \% \mathrm{CI}: 1.1,1.4, \mathrm{P}=0.02)$ and hypertension/pre-hypertension ( $\mathrm{RR}=1.66,95 \% \mathrm{CI}$ : 1.2, 2.4, $\mathrm{P}=0.007)$. However, we found no differences in spatial mobility (based GPS data) among participants who reported living in neighborhoods with and without spatial stigma $(\mathrm{P}>0.05)$. Further research is needed to investigate how placebased stigma may be associated with impaired cardiovascular health among individuals in stigmatised neighborhoods to inform effective cardiovascular risk reduction interventions.
\end{abstract}




\section{Introduction}

Obesity and hypertension persist as major public health problems because of their high prevalence and associated co-morbidities. Obesity is a risk factor for type 2 diabetes (Nguyen et al., 2008; Guh et al., 2009), cardiovascular disease (Guh et al., 2009), hypertension (Nguyen et al., 2008), certain cancers (Guh et al., 2009), and liver disease (Karlas et al., 2013; Shulman, 2014). Hypertension is a risk factor for cardiovascular disease, kidney disease, and stroke (WHO, 2013). From the National Health and Nutrition Examination Survey (NHANES) 2011-2012, the prevalence of obesity among United States adults was estimated at $34.9 \%$ (Ogden et al., 2014), while the prevalence of hypertension was 29.1\% (Nwankwo et al., 2013).

There are long-standing socio-economic disparities in obesity and hypertension rates in the United States, especially stark among lowincome populations in the United States. Low-income populations have higher obesity and hypertension rates compared to the general population (Clarke et al., 2009; Rossen and Schoendorf, 2012; Decker et al., 2013; Krieger et al., 2014). NHANES 2007-2010 data indicates that the prevalence of obesity among low-income adults (classified as below $138 \%$ of the federal poverty line) was nearly $40 \%$ (Decker et al., 2013). In addition to low socioeconomic status being associated with higher mean blood pressure and hypertension prevalence, low-income individuals are less likely to receive treatment for their elevated blood pressure levels and have their hypertension optimally controlled (Colhoun et al., 1998; Ostchega et al., 2008; Brummett et al., 2011; Egan et al., 2014; Krieger et al., 2014). Research also has documented high rates of obesity and hypertension among low-income housing residents (Digenis-Bury et al., 2008; Duncan et al., 2014c). For example, one Boston study found that the prevalence of self-reported hypertension among low-income housing residents was more than two times higher than the rate of hypertension among non-low-income housing residents (Digenis-Bury et al., 2008). Additionally, low-income housing residents were nearly two times more likely to be obese than non-lowincome housing residents (Digenis-Bury et al., 2008).

Research shows that the spatial context, including the neighborhood environment, can influence obesity and hypertension rates (Kawachi and Berkman, 2003; Bennett et al., 2008). For instance, neighborhoods with poor walkability, low neighborhood safety, high fast-food restaurant density, and low supermarket density have been shown to have higher obesity rates (Rundle et al., 2007; Duncan et al., 2009, 2014d; Saelens et al., 2012; Lovasi et al., 2013; Stark et al., 2013; Pham do et al., 2014; Troped et al., 2014). These factors have also been associated with higher rates of hypertension (Chaix et al., 2008; Mujahid et al., 2008; Unger et al., 2014). Other neighborhood characteristics associated with obesity and hypertension include social disorder (e.g. alcohol use, prostitution, drug addiction), physical disorder (e.g. broken windows, vandalism, litter, empty alcohol containers), and neighborhood violence, all of which may be sources of psychosocial stress and thus a potential mechanism connecting these neighborhood characteristics and deleterious cardio-metabolic health outcomes (Bennett et al., 2007; Mujahid et al., 2011; Lovasi et al., 2013). These dimensions of neighborhoods have received substantial attention over the last several decades.

Other neighborhood-related factors can result in psychosocial stress. For example, spatial stigma, or the negative representations of place that are attached to neighborhoods may have deleterious effects on the health of residents via psychosocial stress, among other potential pathways (Keene and Padilla, 2014). Spatial stigma has also been defined by the co-occurrence of its components: labeling, stereotyping, separa- tion, status loss and discrimination (Chaix, 2009). Spatial stigma can include overall neighborhood reputation, media image of the respondents' neighborhood, negative perception of low-income housing residents, and feelings of judgment due to living in subsidised housing. Stigmatised neighborhoods and residents of those neighborhoods may be viewed poorly by the media, individuals living outside the neighborhood, and/or residents themselves. Consequently, these stigmatised neighborhoods or marginalised places can carry negative symbolic meanings that have implications for the health and well being of their residents. Despite evidence demonstrating the associations between neighborhood factors and cardiovascular health outcomes, the role of spatial stigma in obesity and hypertension disparities remains underexplored (Chaix, 2009), including among low-income populations. Previous research has highlighted the salience of spatial stigma on the lives of low-income residents, but has been theoretical in nature and/or has predominantly utilised qualitative methods with limited generalisability and ability to draw associations between spatial stigma and measured cardiovascular health outcomes (Sampson and Raudenbush, 2004; Thompson et al., 2007; Keene and Padilla, 2010, 2014; Kelaher et al., 2010; Tabuchi et al., 2012).

Because very little empirical work has been conducted to examine the potential role of spatial stigma as it relates to cardiovascular health, including obesity and hypertension, in low-income populations, the aim of this study was to examine the relationship between spatial stigma, body mass index and blood pressure among a sample of lowincome housing residents in New York City. Based on the previous theoretical and empirical research, we hypothesised that perceived spatial stigma would be associated with impaired cardiovascular health (i.e. elevated body mass index and/or blood pressure) among low-income housing residents in New York City. In a sub-analysis we incorporate global positioning systems (GPS) data to investigate whether participants with and without spatial stigma have different mobility patterns, which has not been evaluated previously and may help us understand why spatial stigma could matter for cardiovascular health profiles. In addition, we sought to investigate if individuals who spend more time in their residential neighborhoods are more sensitive to spatial stigma. We hypothesised that individuals who report living in neighborhoods with spatial stigma will be more spatially mobile and that individuals who spent more time in their residential neighborhood would be more sensitive to spatial stigma.

\section{Materials and Methods}

\section{Study sample}

Data used in this study come from the NYC Low-Income Housing, Neighborhoods and Health Study ( $n=120)$ (Duncan et al., 2014c; Duncan and Regan, 2015). Recruitment was conducted through community-based outreach, which included handing out flyers outside of public housing developments in four different New York City neighborhoods, as well as through flyers posted and circulated by communitybased organisations that work with low-income individuals (especially public housing residents), flyers posted in community locations (e.g. local stores) and through word of mouth (social networks). Adults were considered eligible for participation in the study if they self-reported living in low-income housing (e.g. public housing) in New York City; were 18 years of age or older; could speak and read English; self-reported not being pregnant; self-reported no difficulty in walking or climbing stairs; and were willing to wear a Global Positioning Systems (GPS) device (on their person; e.g. in their pocket) for one week. The vast 
majority $(80 \%)$ of the participants reported living in public housing (versus other low-income housing) and all participants reported being low-income (e.g. $5.8 \%$ of participants in the study reported living in Section 8 housing). We collected survey and objectively measured health (height, weight and blood pressure) data, which were collected in our research office. Data were collected between June and July 2014. Informed consent was obtained from all participants prior to data collection. We geocoded participant address data using methods used in our past work (Duncan et al., 2011a, 2011b) in order to determine and map their neighborhood of residence. The participants came from 4 of the 5 New York City boroughs, 28 ZIP codes, 21 community districts, 17 United Hospital Fund (UHF)-defined neighborhoods, 41 census tracts and 50 census block groups, which are various ways to define neighborhoods in New York City (Duncan et al., 2014a). See Figure 1 for the spatial distribution of the overall sample by borough, which shows that the majority of participants come from Manhattan (65.8\%). The New York University School of Medicine Institutional Review Board reviewed and approved the research protocol.

\section{Spatial stigma}

We assessed spatial stigma using a four-item survey informed by prior work on spatial sigma and health disparities (Sampson and Raudenbush, 2004; Thompson et al., 2007; Keene and Padilla, 2010, 2014; Kelaher et al., 2010; Tabuchi et al., 2012). The first item was Overall, what is the reputation of your neighborhood? Response options included: Good; Moderate; Bad and Don't know/Not sure. The second item was Overall, is the image of your neighborhood in the media positive? Response options were: Yes; No; and Don't know/Not sure. The third item was According to you, are people who live in your neighborhood seen negatively outside the neighborhood? Response options included: Yes; No; and Don't know/Not sure. The fourth item was Do you feel that people judge you because you live in low-income or subsidised housing? Response options included: Yes; No; and Don't know/Not sure.

\section{Body mass index}

Following standard protocols, trained research assistants (medical students) measured the participant's height and weight. Participants were asked to remove their shoes, heavy outer clothing, hats, and any tall hair accessories prior to measurement of height and weight. Height was measured to the nearest tenth of a centimeter using a Seca 213 stadiometer, with each participant's back to the stadiometer and their head in the Frankfort position (Geeta et al., 2009; Abidin and Adam, 2013; Bacardí-Gascón et al., 2013; McGurk et al., 2013; Prushansky et al., 2013) Weight was measured to the nearest tenth of a kilogram with a Tantina 351 scale (Geeta et al., 2009; Thomas et al., 2010; Yahia et al., 2011; Bacardí-Gascón et al., 2013; Bammann et al., 2013). Body mass index (BMI) was calculated using the standard formula of weight $(\mathrm{kg}) /[\text { height }(\mathrm{cm}) / 100]^{2}$. Underweight is classified as a BMI less than 18.50; normal weight is classified as a BMI 18.50 to 24.99; overweight is classified as a BMI 25.00 to 29.99; and obesity is classified as a BMI above 30.00 .

\section{Blood pressure}

The research assistants were also trained to measure each participant's blood pressure following standard protocols. Participants sat silently in a chair prior to and during measurement of their blood pressure with their arms outstretched, back supported, legs uncrossed and feet on the floor. After being seated for 15 to 30 seconds, we measured their blood pressure with a Welch Allyn Vital Signs 300 monitor (Hess et al., 2007; Victor et al., 2011; Ravenell et al., 2013). Consistent with the most recent Joint National Committee (JNC 8) guidelines, hypertension is classified as a systolic blood pressure greater than 140 $\mathrm{mmHg}$, a diastolic blood pressure greater than $90 \mathrm{mmHg}$ or self-reported use of blood pressure lowering medications. Pre-hypertension is classified as a systolic blood pressure between $120-139 \mathrm{mmHg}$, or a diastolic blood pressure between $80-89 \mathrm{mmHg}$. Normal blood pressure is classified as a systolic blood pressure less than $120 \mathrm{mmHg}$ and a diastolic blood pressure less than $80 \mathrm{mmHg}$.

\section{Global positioning system data processing}

Consistent with other studies (Zenk et al., 2011; Hurvitz and Moudon, 2012; McCluskey et al., 2012; Wiehe et al., 2013; Yan et al., 2014; Clark et al., 2014; Dessing et al., 2014; Harrison et al., 2014; Klinker et al., 2014; Yen et al., 2015), GPS tracking of the sample was conducted for one week. Prior to distribution, we programmed the GPS device to $\log$ in 30-second intervals (so if a participant wore the GPS device for an hour, and had no data loss it would have 120 GPS points recorded) (Duncan et al., 2014c). During the study orientation and baseline assessment, participants were instructed to place the small QStarz's BT-Q1000XT GPS device on their belt (using the manufacturer-provided case) or in their pocket and to complete a travel diary. Participants were asked to wear the GPS units at all times, expect when sleeping, swimming or showering. Consisting of a series of checkboxes, the travel diary asked the participant questions related to GPS protocol compliance, Did you charge the GPS monitor today? and Did you carry the GPS monitor with you today? This was meant to help the participant remember to charge the unit and carry it with him or her throughout the week. The GPS device was given to participants in a large plastic zipper storage bag, which also contained a mini USB charging cord for the GPS device, a USB wall adapter for charging, a manufacturer-provided GPS belt holder (if requested), a pamphlet containing background information on GPS and the travel diary. Upon completion of the week-long GPS protocol (i.e. carrying the unit for all journeys, charging the unit daily, and completing the travel diary), we went

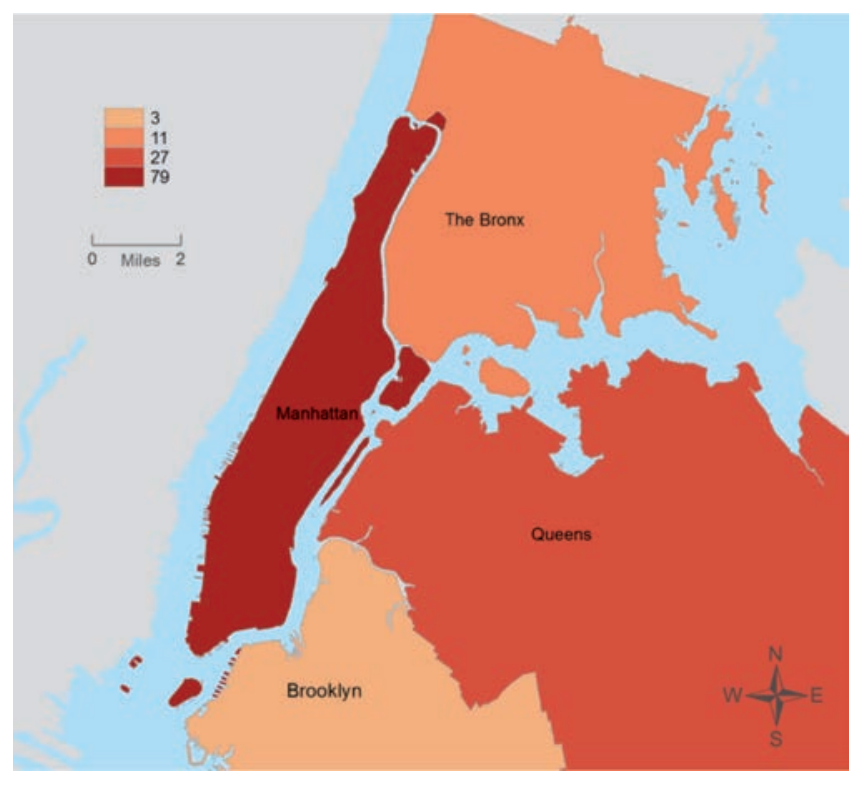

Figure 1. Number of participants by borough, New York City Low-income Housing, Neighborhoods, and Health Study. 
to community locations (i.e. coffee shop, library) in the participant's neighborhood to obtain the GPS devices or participants returned to the project office to give back the GPS devices, depending on which option was most convenient for the individual. Participants compliance was high with a GPS return rate of $95.6 \%$, and 114 of the overall study population had GPS data (Duncan et al., 2014c). GPS participant data was downloaded using the Qstarz proprietary software and stored as .gpx files. The GPS data was then cleaned using several scripts written in the python programming language and ArcGIS Models to eliminate duplicate data, GPS points likely caused by multipath reflectance, GPS data likely caused by timing errors, and isolated GPS data (Python Software Foundation. Python Language Reference, version 2.7. Available at: http://www.python.org) and ArcGIS version 10.2 (ESRI, Redlands, CA, USA).

\section{Global positioning system activity space size calcula- tion and percent time in residential neighborhoods}

Global positioning system activity space buffers were created using ArcGIS version 10 (ESRI). There are various ways to define an activity space (e.g. convex hull, one standard deviation ellipse and daily path area) as well as various distance thresholds for these measures (Zenk et al., 2011; Christian, 2012). In this study, we used a daily path area (a buffering zone drawn around the GPS tracks), which is a common method in behavioral geography research to understand where participants spend the majority of their time and exposure to environments (Zenk et al., 2011; Christian, 2012). Consistent with previous research (Zenk et al., 2011; Christian, 2012), we buffered all the pre-processed GPS points at 0.5 mile and dissolved these separate features into a single feature, or space to create an activity space for each participant. A half-mile was selected to capture the immediate vicinity around activity locations, general area of exposure, and travel routes. While the literature is mixed on a common buffer size, one half-mile was selected because it has been shown to give a good estimate of exposure based on walkability studies, and is a commonly used distance in physical activity studies (Frank et al., 2004; Cohen et al., 2006; Troped et al., 2010). The activity space size was expressed in square miles. In addition, we calculated the percent of GPS points within the residential neighborhood (i.e. percent of time spent in the neighborhood). Neighborhoods were defined as 400 - and 800 -meter street network buffers around one's residential address (Rundle et al., 2009; Duncan et al., 2011a, 2012, 2014b, 2014d; Jilcott et al., 2011; Leung et al., 2011; Schwartz et al., 2011; Duncan and Hatzenbuehler, 2014; Reitzel et al., 2014; James et al., 2014; Troped et al., 2014).

\section{Other variables}

Age categories included 18-24, 25-44, and 45+. Gender categories included male and female. Race/ethnicity categories included Black/African American, Asian/Asian American, Hispanic, White/Caucasian, and Other. Education levels included less than a $12^{\text {th }}$ grade education, high school degree or GED, some college or vocational school, completion of bachelor's degree, and completion of graduate degree. Employment status groups were defined as full-time, part-time, unemployed, and retired/school. Household income included $<\$ 25,000$, $\$ 25,000-\$ 49,999, \$ 50,000-\$ 74,999$, and $\$ 75,000+$ categories. In addition, neighborhood percent non-Hispanic Black and neighborhood median household income at the census block group level were calculated using geographic information systems (GIS) software using data from the 2010 US Census and the 2009-2013 American Community Survey (United States Census Bureau, 2010).

\section{Statistical analyses}

The analytic sample for the primary analyses included only participants who answered all four spatial stigma items ( $n=116 ; 96.7 \%)$. Using this restricted sample, we first generated descriptive statistics for the sample by participant demographics. Then, we computed descriptive statistics for all spatial stigma items and set all stigma responses of Don't know/Not sure to missing. In analysing the GPS data to determine whether participants with and without spatial stigma have different mobility patterns, we first used a measure of activity space size. Additionally, we investigated whether individuals with larger proportions of time exposed to their residential neighborhoods were more sensitive to spatial stigma, using GPS percent of time in residential buffers (400 and 800 meter network buffers). Analyses for activity space size used simple linear regression, and those for network buffers used generalised linear modeling with a logit link and a binomial distribution with robust standard errors.

After this, we fit a series of multivariable models including each of the four spatial stigma items. In particular, each model included only one spatial stigma item in light of potential multicollinearity. Outcomes for multivariable analyses included BMI, systolic blood pressure, diastolic blood pressure, overweight/obesity status, and hypertension/prehypertension status. A series of five regression models were constructed. Three linear regression models included BMI and blood pressure (for systolic and diastolic) as continuous dependent variables. Overweight-obesity and pre-hypertension-hypertension status were dichotomised into overweight-obese versus not and pre-hypertensivehypertensive versus not groups and used in two regression models.

The degree of potential clustering due to neighborhood effects was estimated using intercept-only random-effects linear and logistic regression models, clustered by census block group. Large intraclass correlelation coefficients were found for diastolic blood pressure (18.9\%) and hypertension/pre-hypertension status (24.0\%). For diastolic and hypertensive/pre-hypertensive models, regression analyses utilised clustered robust standard errors due to large ICC levels.

As overweight/obese and pre-hypertensive/hypertensive status are common in our study sample, odds ratios were likely to overestimate the effect (Thompson et al., 1998; McNutt et al., 2003; Behrens et al., 2004; Schmidt and Kohlmann, 2008). Therefore, relative risks (RRs; i.e., prevalence ratios) were calculated rather than odds ratios. Odds ratios were obtained using logistic regression and converted to relative risks. Modified Poisson regression with clustered robust variances were used to estimate relative risks for the hypertension/prehypertension model. Covariates for all models included individual-level age, gender, race/ethnicity, education level, employment status, total household income neighborhood percent non-Hispanic Black (continuous variable) and neighborhood median household income (continuous variable). Statistical analysis was performed using Stata version 13 (Stata Corp; College Station, TX, USA). All P values reported are twosided. Statistical significance was evaluated by $95 \%$ confidence intervals (CIs) and P values less than 0.05 .

\section{Results}

Table 1 presents socio-demographic characteristics of the sample of low-income housing residents. Over half $(56 \%)$ of the sample was female, $68 \%$ were Black/African American, and 39\% were 45 years or older. A large proportion of the sample was obese and/or hypertensive: $40 \%$ were obese and $38 \%$ of the sample was hypertensive. Slightly over half (52\%) reported a moderate neighborhood reputation, while $21 \%$ 
reported their neighborhood reputation as bad (Table 2). Almost 36\% reported that the media did not positively view their neighborhood. $41 \%$ reported negative external perception and $58 \%$ reported that they feel judged from living in low-income housing.

We found no differences in spatial mobility (based on GPS data) among participants who reported living in neighborhoods with and with out spatial stigma $(\mathrm{P}>0.05)$ (Table 2). For example, participants reporting living in a neighborhood with a good reputation had a mean activity space of 13.8 square miles, living in a neighborhood with a moderate reputation had a mean activity space of 12.7 square miles, and living in a neighborhood with a bad reputation had a mean activity space of 12.3 square miles $(\mathrm{P}=0.89)$. Moreover, we found that individuals exposed to a larger fraction of their time to their residential neighborhood were not more sensitive to spatial stigma $(\mathrm{P}>0.05)$. For example, participants reporting living in a neighborhood with a good reputation spent $52.6 \%$ of time in their residential neighborhood (400-meter network buffer), living in a neighborhood with a moderate reputation spent $59.9 \%$ of time in their residential neighborhood (400-meter network buffer), and living in a neighborhood with a bad reputation spent $43.7 \%$ of time in their residential neighborhood (400-meter network buffer) $(\mathrm{P}=0.35)$. Multivariable models of spatial stigma, BMI and blood pressure are shown in Table 3. Participants who reported living in an area that had a bad neighborhood reputation had higher BMI ( $\mathrm{B}=4.2,95 \% \mathrm{CI}$ : $-0.01,8.3, \mathrm{P}=0.051$ ), as well as higher systolic blood pressure $(\mathrm{B}=13.2,95 \% \mathrm{CI}$ : $3.2,23.1, \mathrm{P}=0.01)$ and diastolic blood pressure ( $\mathrm{B}=8.5,95 \% \mathrm{CI}: 2.8,14.3, \mathrm{P}=0.004)$. In addition, participants who reported living in an area with a bad neighborhood reputation had increased prevalence of obesity/overweight $(\mathrm{RR}=1.32,95 \% \mathrm{CI}$ : 1.1, 1.4, $\mathrm{P}=0.02)$ and hypertension/pre-hypertension ( $\mathrm{RR}=1.66,95 \% \mathrm{CI}: 1.2,2.4$, $\mathrm{P}=0.007$ ). Finally, we found that reporting feeling judged from living in public housing have lower diastolic blood pressure $(B=-5.5,95 \% \mathrm{CI}$ : $10.2,-0.66, \mathrm{P}=0.027)$.

\section{Discussion}

No study, to our best knowledge, has quantitatively assessed relationships between spatial stigma and cardiovascular health, especially among low-income housing residents who traditionally have high rates

Table 1. Socio-demographic characteristics of the sample of New York City low-income housing residents (n=116).

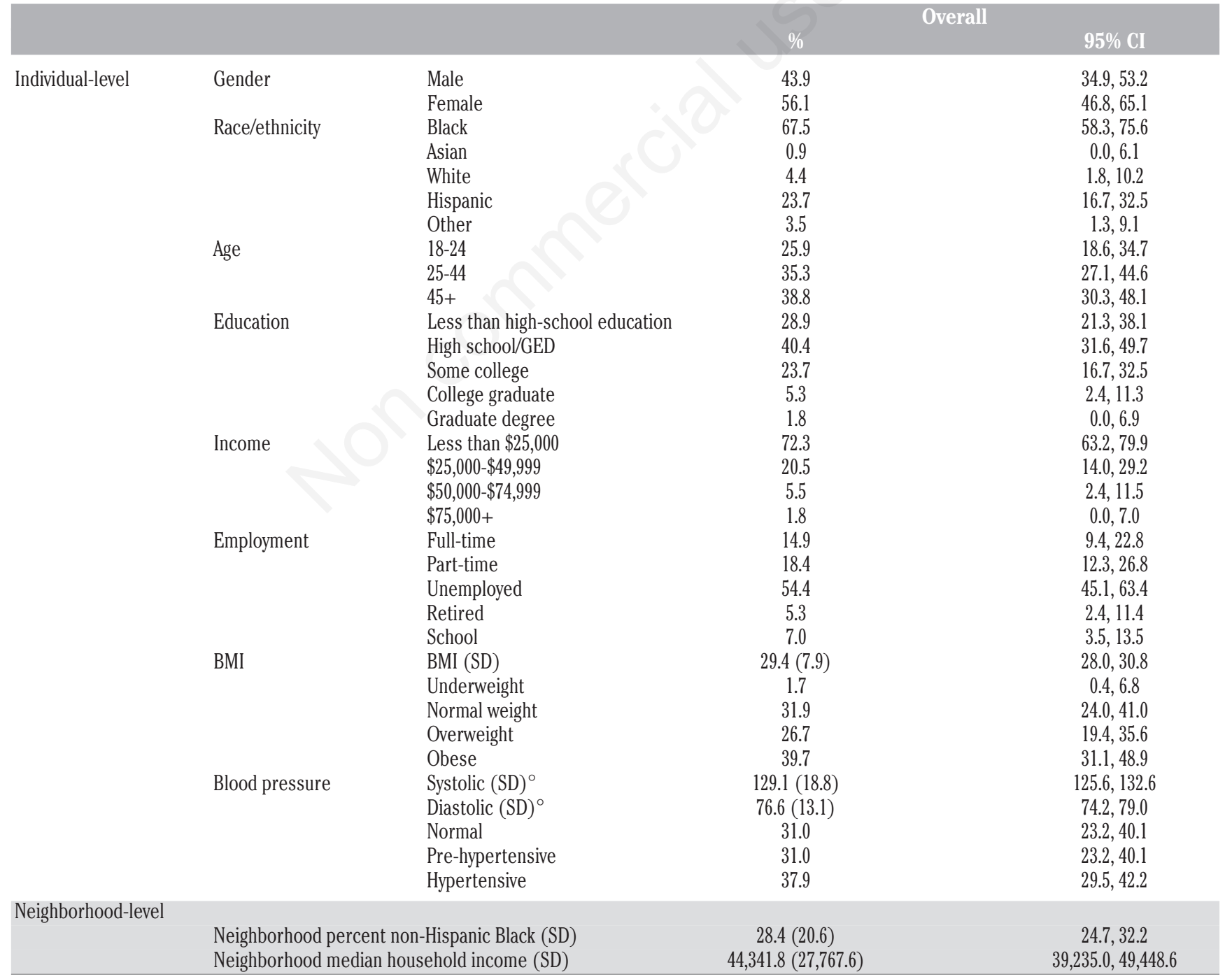

$\mathrm{Cl}$, confidence interval; GED, general educational development; BMI, body mass index; SD, standard deviation. ${ }^{\circ}$ Values are expressed as mmHg. 
of obesity and hypertension (Digenis-Bury et al., 2008; Duncan et al., 2014c). In this study, we primarily sought to evaluate relationships between spatial stigma, BMI, and blood pressure among a sample of low-income housing residents in New York City. We found that a bad neighborhood reputation was associated with increased BMI, as well as related to increases in both systolic and diastolic blood pressure. We also found that participants who reported living in an area with a bad neighborhood reputation had increased prevalence of obesity/overweight and hypertension/pre-hypertension. This highlights that neighborhood reputation as compared with the other dimensions of spatial stigma may be the most salient aspect related to cardiovascular health, as other dimensions of spatial stigma were not associated with body mass index or blood pressure.

While the connection between spatial stigma and health is fairly understudied, our overall results complement past theoretical and qualitative literature on spatial stigma and health disparities. This past research has suggested that spatial stigma acts as a psychosocial stressor and can contribute to a range of physical and mental health out- comes (Sampson and Raudenbush, 2004; Keene and Padilla, 2010, 2014; Kelaher et al., 2010; Tabuchi et al., 2012). Negative place-based identity from neighborhoods can be transferred to the residents of these neighborhoods who incorporate this identity, which negatively affects their behavior. High levels of spatial stigma may induce stress, which is in turn associated with increased BMI and blood pressure. The stress from spatial stigma may be due in part to individuals who reside in stigmatised neighborhoods (e.g. high-poverty neighborhoods) facing daily discrimination when others view them negatively because of where they live, such as discrimination based on negative stereotypes that people hold about certain neighborhoods. In addition, another possible mechanism is through more depressive feelings related to altered individual identity as affected by the negative collective identify (Tabuchi et al., 2012): that is, spatial stigma can produce a negative view of self, which in turn can affect absence of efforts to manage one's body weight, to monitor one's blood pressure (Chaix, 2009). This discrimination may also limit people's economic and health-promoting opportunities. Specifically, it has been postulated that spatial stigma

Table 2. Prevalence of spatial stigma in New York City Low-income Housing, Neighborhoods and Health Study.

\begin{tabular}{|c|c|c|c|c|c|c|c|c|}
\hline & & $\begin{array}{l}\text { Percent of overall } \\
\text { (analytic sample) } \\
(\mathrm{n}=116)\end{array}$ & $\begin{array}{l}\text { Mean of activity } \\
\text { space size } \\
(n=102)\end{array}$ & P* & $\begin{array}{l}\text { Percent in } \\
\text { residential } \\
\text { buffer } \\
\text { (400-meters) }\end{array}$ & P* & $\begin{array}{l}\text { Percent in } \\
\text { residential } \\
\text { buffer } \\
\text { ( } 800 \text {-meters) }\end{array}$ & P* \\
\hline Neighborhood reputation & $\begin{array}{l}\text { Good } \\
\text { Moderate } \\
\text { Bad } \\
\text { Don't know/not sure }\end{array}$ & $\begin{array}{c}19.8 \\
51.7 \\
20.7 \\
7.8\end{array}$ & $\begin{array}{l}13.8 \\
12.7 \\
12.3 \\
15.9\end{array}$ & .89 & $\begin{array}{l}52.6 \\
59.9 \\
43.7 \\
48.8\end{array}$ & .35 & $\begin{array}{l}59.1 \\
65.8 \\
54.0 \\
58.1\end{array}$ & .57 \\
\hline Positive media image & $\begin{array}{l}\text { Yes } \\
\text { No } \\
\text { Don't know/not sure }\end{array}$ & $\begin{array}{l}27.6 \\
35.3 \\
37.1 \\
\end{array}$ & $\begin{array}{l}14.7 \\
13.6 \\
12.6\end{array}$ & .69 & $\begin{array}{l}56.8 \\
48.5 \\
57.0\end{array}$ & .87 & $\begin{array}{l}62.3 \\
57.4 \\
64.5\end{array}$ & .73 \\
\hline Negative external perception & $\begin{array}{l}\text { Yes } \\
\text { No } \\
\text { Don't know/not sure }\end{array}$ & $\begin{array}{l}40.5 \\
27.6 \\
31.9\end{array}$ & $\begin{array}{l}13.8 \\
14.5 \\
11.8\end{array}$ & .77 & $\begin{array}{l}52.2 \\
54.4 \\
59.7\end{array}$ & .37 & $\begin{array}{l}62.2 \\
59.5 \\
66.5\end{array}$ & .64 \\
\hline Feel judged from housing & $\begin{array}{l}\text { Yes } \\
\text { No } \\
\text { Don't know/not sure }\end{array}$ & $\begin{array}{l}57.8 \\
24.1 \\
18.1\end{array}$ & $\begin{array}{l}14.6 \\
12.2 \\
11.0\end{array}$ & .32 & $\begin{array}{l}53.4 \\
52.8 \\
57.7\end{array}$ & .69 & $\begin{array}{l}61.4 \\
58.9 \\
64.7\end{array}$ & .81 \\
\hline
\end{tabular}

*P trend for neighborhood reputation (all hypothesis tests set Don't know/not sure to missing).

Table 3. Multivariable models of spatial stigma, body mass index and blood pressure ( $\mathrm{n}=116)$.

\begin{tabular}{|c|c|c|c|c|c|c|c|c|c|c|c|c|c|c|}
\hline & & \multicolumn{3}{|c|}{$\begin{array}{l}\text { Model 1: } \\
\text { BMI }\end{array}$} & \multicolumn{3}{|c|}{$\begin{array}{l}\text { Model 2: } \\
\text { Obese/overweight } \\
\text { vs Not }\end{array}$} & \multicolumn{2}{|c|}{$\begin{array}{l}\text { Model 3: } \\
\text { Blood pressure } \\
\text { (systolic) }\end{array}$} & \multicolumn{2}{|c|}{$\begin{array}{l}\text { Model 4: Blood } \\
\text { pressure } \\
\text { (diastolic) }\end{array}$} & \multicolumn{3}{|c|}{$\begin{array}{l}\text { Model 5: } \\
\text { HTN/Pre-HTN } \\
\text { vs Not }\end{array}$} \\
\hline & & $\beta$ & $95 \% \mathrm{CI}$ & $P$ & RR & $95 \% \mathrm{CI}$ & P & $\beta \quad 95 \% \mathrm{CI}$ & $\mathrm{P}$ & $\beta \quad 95 \% \mathrm{CI}$ & $P$ & RR & $95 \% \mathrm{CI}$ & P \\
\hline $\begin{array}{l}\text { Neighborhood } \\
\text { reputation }\end{array}$ & $\begin{array}{l}\text { Good (ref) } \\
\text { Moderate } \\
\text { Bad }\end{array}$ & $\begin{array}{l}- \\
-.07 \\
4.2\end{array}$ & $\begin{array}{c}- \\
-3.5,3.4 \\
-.01,8.3\end{array}$ & $\begin{array}{l}- \\
.97 \\
.051\end{array}$ & $\begin{array}{c}- \\
.92 \\
1.32\end{array}$ & $\begin{array}{c}- \\
.55,1.2 \\
1.1,1.4\end{array}$ & $\begin{array}{l}- \\
.61 \\
0.02\end{array}$ & $\begin{array}{cc}- & - \\
7.3 & -.92,15.4 \\
13.2 & 3.2,23.1\end{array}$ & $\begin{array}{c}- \\
.081 \\
0.01\end{array}$ & $\begin{array}{cc}- & - \\
.68 & -4.3,5.6 \\
8.5 & 2.8,14.3\end{array}$ & $\begin{array}{c}- \\
.784 \\
.004\end{array}$ & $\begin{array}{c}- \\
1.31 \\
1.66\end{array}$ & $\begin{array}{c}- \\
.97,1.8 \\
1.2,2.4\end{array}$ & $\begin{array}{c}- \\
.075 \\
.007\end{array}$ \\
\hline Positive media image & $\begin{array}{l}\text { Yes (ref) } \\
\text { No }\end{array}$ & $\overline{-}$ & $-3.3,5.4$ & $\begin{array}{c}- \\
.627\end{array}$ & 1.19 & $.70,1.5$ & $\begin{array}{c}- \\
.43\end{array}$ & $\begin{array}{cc}- & - \\
-6.4 & -16.7,3.9\end{array}$ & .218 & $\begin{array}{cc}- & - \\
-.64 & -8.4,7.1\end{array}$ & $\overline{-} \cdot$ & $\overline{8}$ & $\stackrel{-}{65,1.0}$ &. \\
\hline $\begin{array}{l}\text { Negative external } \\
\text { perception }\end{array}$ & $\begin{array}{l}\text { No (ref) } \\
\text { Yes }\end{array}$ & $\begin{array}{c}- \\
1.3\end{array}$ & $-2.7,5.2$ & .518 & $\begin{array}{l}- \\
.97\end{array}$ & $.57,1.2$ & 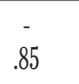 & $-4.96-14.5,4.6$ &. & $\begin{array}{cc}- & - \\
-1.98 & -8.8,4.9\end{array}$ & $\begin{array}{c}- \\
.561\end{array}$ & $\begin{array}{c}- \\
.85\end{array}$ &. & $\begin{array}{c}- \\
.252\end{array}$ \\
\hline Feel judged from housing & $\begin{array}{l}\text { No (ref) } \\
\text { Yes }\end{array}$ & $\begin{array}{c}- \\
-.77\end{array}$ & $-4.3,2.8$ & - & - & $\stackrel{-}{.}$ & $\begin{array}{l}- \\
.87\end{array}$ & $-\overline{-}-\overline{-}$ &. & $-5.5-10.2,-.66$ & $\begin{array}{c}- \\
.027\end{array}$ & $\begin{array}{c}- \\
.86\end{array}$ & $\begin{array}{c}- \\
.67,1.1\end{array}$ & $\begin{array}{c}- \\
.241\end{array}$ \\
\hline
\end{tabular}

BMI, body mass index; HTN, hypertension; CI, confidence interval; RR, relative risk. All models adjusted for individual-level age, gender, race/ethnicity, income, education, employment status, neighborhood percent non-Hispanic Black and neighborhood median household income. For overall spatial stigma, the reference group is Good perceptions of the neighborhood. For positive media image, reference group is Yes, overall media image is positive. For negative external perception, reference group is No, people in my neighborhood are not seen negatively outside the neighborhood. For housing judgment, reference group is No, people do not judge me because I live in low-income/subsidised housing. 
restricts residents' access to health-promoting resources and limits economic opportunities, and thus contributes to persistent health disparities (Thompson et al., 2007; Keene and Padilla, 2014). For example, employers may discriminate in the hiring process against addresses from disadvantaged neighborhoods (Kirschenman and Neckerman, 1991; Wilson, 1996). In addition, spatial stigma, including neighborhood reputation, can affect the type of resources and opportunities in that neighborhood. It is plausible that certain respected brands might not want their stores to be located in neighborhoods marked by spatial stigma. The finding about being judged from living in public housing being associated with reduced diastolic blood pressure was unexpected. This may suggest that participants in affluent neighborhoods are more judged because in poor neighborhoods as everyone find it normal. So one would only be judged when being in an affluent neighborhood and at the same time living in public housing. In addition, in a subanalysis we incorporated GPS data to investigate whether participants with and without spatial stigma have different spatial mobility patterns and we found no differences. Perhaps spatial mobility is influence by other macro-social factors such as neighborhood poverty. Moreover, we found that individuals exposed to a larger fraction of their time to their residential neighborhood were not more sensitive to spatial stigma. It is unclear why spatial stigma was not more salient to individuals who spend more time in their residential neighborhoods.

Spatial stigma is an illuminating but understudied phenomenon that may contribute to persistent health disparities among low-income and marginalised populations. However, further research is needed. For instance, the role of spatial stigma may vary across different geographic contexts and across different population groups, including non-lowincome populations. Our study only evaluated spatial stigma in lowincome urban environments, and thus future research should continue to evaluate the role of spatial stigma on cardiovascular health as well as other health outcomes in larger samples and samples across different geographies, including in rural locations. Future research could also assess how resilient these findings are across age, gender or racial/ethnic subgroups. In addition, future research can identify mediating mechanisms of behavioral nature (e.g. perhaps increased food intake) or psychological nature (e.g. depression) linking spatial stigma to cardiovascular health. Understanding the mediating role of health behaviors and health states can guide intervention development. While spatial stigma can be measured using individual-level survey research methods, as was done in this study, other research methods can be used, including objective methods such as newspaper reports as well as using an ecometric approach to produce objective indicators of stigma in each neighborhood by aggregating survey responses from different participants residing in this neighborhood (Gauvin et al., 2005; Fone et al., 2006; Mujahid et al., 2007; De Jong et al., 2011; Corsi et al., 2012). For example, researchers could conduct street-intercept surveys with individuals in neighborhoods as previous research has shown that this particular survey method can yield more representative samples when compared to traditional sampling methods (e.g. random digit dialing) (Miller et al., 1997; Ompad et al., 2008) and then aggregate responses to a neighborhood unit for analyses. Furthermore, there is an additional research opportunity to psychometrically develop an instrument of spatial stigma that would assist in these types of research investigations. This future research may help us further understand and eventually reduce health disparities experienced among low-income housing residents. For instance, in addition to structural policy environmental interventions, psychosocial interventions that address spatial stigma may be needed to improve cardiovascular health among residents in low-income housing. Media outlets could be provided with and provide more constructive and de-stigmatising images of low-income neighborhoods and their residents, which could be a public health intervention.

This study is subject to several limitations that we noted here. First, our results may not be generalisable to low-income populations in other non-urban regions of the United States: we had a convenient relatively small sample of low-income housing residents in New York City. Having a small sample size likely reduced power to detect significant effects. However, our sample includes a multi-ethnic sample of lowincome housing residents across different New York City neighborhoods and our study is the first quantitative study of spatial stigma on cardio-metabolic health among the studied population. In addition, while 116 participants is a relatively small sample size for general population, many GPS studies have fewer than 100 participants so the sample sized used here is on par with and even exceeds the sample size of many GPS-based research. Selection bias might also be a concern: we could assume that high BMI negatively influences participation in the study, and that stigma also negatively influences participation. It would cause bias in the spatial stigma BMI association. The selection bias we describe would likely pull the positive association that we document towards the null. In addition, the study was limited to English speaking low-income housing residents, and consequently our findings may not be generalisable to non-English speaking low-income housing populations. While self-report bias can be an issue with self-reported blood pressure as well as self-reported height and weight data, we were able to objectively measure both blood pressure and BMI, which is an important strength of our study. However, blood pressure was calculated by a single measurement. A clinical diagnosis of hypertension usually requires multiple blood pressure measurements and several previous studies have used the average of two or more measurements. The use of a single measurement may overestimate the prevalence of hypertension. Social desirability bias, with regards to perceived spatial stigma, may also be an issue. Furthermore, residual confounding is a potential limitation. For instance, the survey did not evaluate residential history and thus we were not able to control for that. This study was a cross-sectional analysis. As such, our study does not provide evidence that spatial stigma is casually associated with cardiovascular health outcomes. In addition, reserve causation may be a concern. From an environmental psychology point of view, it might be that obese people, if they have a lower self-esteem from this condition, tend to perceive less favorably their neighborhood. If that were true, this reverse causation would contribute to the positive association that we found between spatial stigma and BMI. Finally, there are caveats about the GPS analysis. It should be noted that while GPS data allows for potentially highly accurate point locations of participants, these data may be limited when the GPS receiver cannot find enough satellites to triangulate its location. In addition after a long period without satellite communication, GPS receivers may take additional time to acquire a fix location and these issues are exacerbated in cities with many think and tall concrete buildings. Additionally, while the GPS analysis by spatial stigma indicators is very novel, we must note that the modifiable areal unit problem is a limitation. In particular, the selected buffer size around the GPS points could have influenced the findings.

\section{Conclusions}

In conclusion, overall perceived spatial stigma was significantly associated with increased BMI, as well as significantly related to increases in both systolic and diastolic blood pressure. We also found that participants who reported living in an area with a bad neighbor- 
hood reputation had increased risk of obesity/overweight and hypertension/pre-hypertension. Further research is needed to investigate how place-based stigma may be associated with impaired cardiovascular health among individuals in stigmatised neighborhoods to inform effective cardiovascular risk reduction and quality-of-life interventions.

\section{References}

Abidin NZ, Adams MB, 2013. Prediction of vertical jump height from anthropometric factors in male and female martial arts athletes. Malays J Med Sci 20:39.

Bammann K, Huybrechts I, Vicente-Rodriguez G, Easton C, De Vriendt T, Marild S, Mesana M, Peeters MW, Reilly JJ, Sioen I, Tubic B, Wawro N, Wells JC, Westerterp K, Pitsiladis Y, Moreno LA, IDEFICS Consortium, 2013. Validation of anthropometry and foot-to-foot bioelectrical resistance against a three-component model to assess total body fat in children: the IDEFICS study. Int J Obesity 37:5206.

Barcadí-Gascón M, Jones EG, Jiménez-Cruz A, 2013. Prevalence of obesity and abdominal obesity from four to 16 years old children living in the Mexico-USA border. Nutr Hosp 28:479-85.

Behrens T, Taeger D, Wellmann J, Keil U, 2004. Different methods to calculate effect estimates in cross-sectional studies. A comparison between prevalence odds ratios and prevalence ratio. Method Inform Med 43:505-9.

Bennett GG, McNeill LH, Wolin KY, Duncan DT, Puleo E, Emmons KM, 2007. Safe to walk? Neighborhood safety and physical activity among public housing residents. PLoS Med 4:1599-606.

Bennett GG, Wolin KY, Duncan DT, 2008. Social determinants of obesity. In: Hu F (ed.) Obesity epidemiology: methods and applications. Oxford University Press, Oxford, UK. pp. 342-76.

Brummett BH, Babyak MA, Siegler IC, Shanahan M, Harris KM, Elder GH, Williams RB, 2011. Systolic blood pressure, socioeconomic status, and biobehavioral risk factors in a nationally representative US young adult sample. Hypertension 58:161-6.

Chaix B, 2009. Geographic life environments and coronary heart disease: a literature review, theoretical contributions, methodological updates, and a research agenda. Annu Rev Publ Health 30:81-105.

Chaix B, Bucimetière P, Lang T, Haas B, Montaye M, Ruidavets JB, Arbeiler D, Amouyel P, Ferrières J, Bingham A, Chauvin P, 2008. Residential environment and blood pressure in the PRIME study: is the association mediated by body mass index and waist circumference? J Hypertens 26:1078-84.

Christian WJ, 2012. Using geospatial technologies to explore activitybased retail food environments. Spat Spatiotemporal Epidemiol 3:287-95.

Clark RA, Weragoda N, Paterson K, Telianidis S, Williams G, 2014. A pilot investigation using global positioning systems into the outdoor activity of people with severe traumatic brain injury. J Neuroeng Rehabil 11:37.

Clarke P, O'Malley PM, Johnston LD, Schulenberg JE, 2009. Social disparities in BMI trajectories across adulthood by gender, race/ethnicity and lifetime socio-economic position: 1986-2004. Int J Epidemiol 38:499-509.

Cohen DA, Ashwood JS, Scott MM, Overton A, Evenson KR, Staten LK, Porter D, McKenzie TL, Catellier D, 2006. Public parks and physical activity among adolescent girls. Pediatrics 118:e1381-9.

Colhoun HM, Hemingway H, Poulter NR, 1998. Socio-economic status and blood pressure: an overview analysis. J Hum Hypertens 12:91-110.
Corsi DJ, Subramanian SV, McKee M, Li W, Swaminathan S, LopezJaramillo P, Avezum A, Lear SA, Dagenais G, Rangarajan S, Teo K, Yusuf S, Chow CK, 2012. Environmental profile of a community's health (EPOCH): an ecometric assessment of measures of the community environment based on individual perception. PLoS One 7:e44410.

De Jong K, Albin M, Skärbäck E, Grahn P, Wadbro J, Merlo J, Björk J, 2011. Area-aggregated assessments of perceived environmental attributes may overcome single-source bias in studies of green environments and health: results from a cross-sectional survey in southern Sweden. Environ Health 10:4.

Decker SL, Kostova D, Kenney GM, Long SK, 2013. Health status, risk factors, and medical conditions among persons enrolled in Medicaid $v s$ uninsured low-income adults potentially eligible for Medicaid under the Affordable Care Act. J Am Med Assoc 309:257986.

Dessing D, De Vries SI, Graham JM, Pierik FH, 2014. Active transport between home and school assessed with GPS: a cross-sectional study among Dutch elementary school children. BMC Public Health 14:227.

Digenis-Bury EC, Brooks DR, Chen L, Ostrem M, Horsburgh CR, 2008. Use of a population-based survey to describe the health of Boston public housing residents. Am J Public Health 98:85-91.

Duncan DT, Aldstadt J, Whalen J, Melly SJ, Gortmaker SL, 2011a. Validation of walk score for estimating neighborhood walkability: An analysis of four US metropolitan areas. Int J Environ Res Public Health 8:4160-79.

Duncan DT, Castro MC, Blossom JC, Bennett GG, Gortmaker SL, 2011b. Evaluation of the positional difference between two common geocoding methods. Geospat Health 5:265-73.

Duncan DT, Castro MC, Gortmaker, Aldstadt J, Melly SJ, Bennett GG, 2012. Racial differences in the built environment-body mass index relationship? A geospatial analysis of adolescents in urban neighborhoods. Int J Health Geogr 11:11.

Duncan DT, Hatzenbuehler ML, 2014. Lesbian, gay, bisexual, and transgender hate crimes and suicidality among a population-based sample of sexual-minority adolescents in Boston. Am J Public Health 104:272-8.

Duncan DT, Johnson RM, Molnar BE, Azrael D, 2009. Association between neighborhood safety and overweight status among urban adolescents. BMC Public Health 9:289.

Duncan DT, Kapadia F, Halkitis PN, 2014a. Examination of spatial polygamy among young gay, bisexual, and other men who have sex with men in New York City: the p18 cohort study. Int J Environ Res Public Health 11:8962-83.

Duncan DT, Kawachi I, Subramanian SV, Alstadt J, Melly SJ, Williams DR, 2014b. Examination of how neighborhood definition influences measurements of youths' access to tobacco retailers: a methodological note on spatial misclassification. Am J Epidemiol 179:373-81.

Duncan DT, Regan SD, 2015. Mapping multi-day GPS data: a cartographic study in NYC. J Maps 12:668-70.

Duncan DT, Regan SD, Shelley D, Day K, Ruff RR, Al-Bayan M, Elbel B, 2014c. Application of global positioning system methods for the study of obesity and hypertension risk among low-income housing residents in New York City: a spatial feasibility study. Geospat Health 9:57-70.

Duncan DT, Shairifi M, Melly SJ, Marshall R, Sequist TD, Rifas-Shiman SL, Taveras EM, 2014d. Characteristics of walkable built environments and BMI z-scores in children: evidence from a large electronic health record database. Environ Health Persp 122:1359-65. 
Egan BM, Li J, Small J, Nietert PJ, Sinopoli A, 2014. The growing gap in hypertension control between insured and uninsured adults: National Health and Nutrition Examination Survey 1988 to 2010. Hypertension 64:997-1004.

Fone DL, Farewell DM, Dunstan FD, 2006. An ecometric analysis of neighbourhood cohesion. Popul Health Metr 4:17.

Frank LD, Andresen MA, Schmid TL, 2004. Obesity relationships with community design, physical activity, and time spent in cars. Am J Prev Med 27:87-96.

Gauvin L, Richard L, Craig CL, Spivock M, Riva M, Forster M, Laforest S, Laberge S, Fournel MC, Gagnon H, Gagne S, Potvin L, 2005. From walkability to active living potential: an ecometric validation study. Am J Prev Med 28:126-33.

Geeta A, Jamaiyah H, Safiza M, Khor G, Kee C, Ahmad A, Suzana S, Rahmah R, Faudzi A, 2009. Reliability, technical error of measurements and validity of instruments for nutritional status assessment of adults in Malaysia. Singapore Med J 50:1013.

Guh DP, Zhang W, Bansback N, Amarsi Z, Birmingham CL, Anis AH, 2009. The incidence of co-morbidities related to obesity and overweight: a systematic review and meta-analysis. BMC Public Health 9:88.

Harrison F, Burgoine T, Corder K, Van Sluijs EM, Jones A, 2014. How well do modelled routes to school record the environments children are exposed to? A cross-sectional comparison of GIS-modelled and GPS-measured routes to school. Int J Health Geogr 13:5.

Hess PL, Reingold S, Jones J, Fellman MA, Knowles P, Ravenell JE, Kim S, Raju J, Ruger E, Clark S, 2007. Barbershops as hypertension detection, referral, and follow-up centers for black men. Hypertension 49:1040-6.

Hurvitz PM, Moudon AV, 2012. Home versus nonhome neighborhood: quantifying differences in exposure to the built environment. Am J Prev Med 42:411-7.

James P, Berrigan D, Hart JE, Hipp JA, Hoehner CM, Kerr J, Major JM, Oka M, Laden F, 2014. Effects of buffer size and shape on associations between the built environment and energy balance. Health Place 27:162-70.

Jilcott SB, Wade S, McGuirt JT, Wu Q, Lazorick S, Moore JB, 2011. The association between the food environment and weight status among eastern North Carolina youth. Public Health Nutr 14:1610-7.

Karlas T, Wiegand J, Berg T, 2013. Gastrointestinal complications of obesity: non-alcoholic fatty liver disease (NAFLD) and its sequelae. Best Pract Res Clin En 27:195-208.

Kawachi I, Berkman L, 2003. Neighborhoods and health. Oxford University Press, New York, NY, USA.

Keene DE, Padilla MB, 2010. Race, class and the stigma of place: moving to opportunity in Eastern Iowa. Health Place 16:1216-23.

Keene DE, Padilla MB, 2014. Spatial stigma and health inequality. Critical Public Health 24:392-404.

Kelaher M, Warr DJ, Feldman P, Tacticos T, 2010. Living in 'Birdsville': exploring the impact of neighbourhood stigma on health. Health Place 16:381-8.

Kirschenman J, Neckerman KM, 1991. 'We'd love to hire them, but...': the meaning of race for employers. The Urban Underclass 203:20332.

Klinker CD, Schipperijin J, Christian H, Kerr J, Ersboll AK, Troelsen J, 2014. Using accelerometers and global positioning system devices to assess gender and age differences in children's school, transport, leisure and home based physical activity. Int J Behav Nutr Phys Act 11:8.

Krieger N, Kosheleva A, Waterman PD, Chen JT, Beckfield J, Kiang MV, 2014. 50-year trends in US socioeconomic inequalities in health:
US-born Black and White Americans, 1959-2008. Int J Epidemiol 43:1294-313.

Leung CW, Laraia BA, Kelly M, Nickleach D, Adler NE, Kushi LH, Yen IH, 2011. The influence of neighborhood food stores on change in young girls' body mass index. Am J Prev Med 41:43-51.

Lovasi GS, Schwartz-Soicher 0, Quinn JW, Berger DK, Neckerman KM, Jaslow R, Lee KK, Rundle A, 2013. Neighborhood safety and green space as predictors of obesity among preschool children from lowincome families in New York City. Prev Med 57:189-93.

McCluskey A, Ada L, Dean CM, Vargas JM, 2012. Feasibility and validity of a wearable GPS device for measuring outings after stroke. ISRN Rehabil 2012:823180.

McGurk P, Jackson JM, Elia M, 2013. Rapid and reliable self-screening for nutritional risk in hospital outpatients using an electronic system. Nutrition 29:693-6.

McNutt LA, Wu C, Xue X, Hafner JP, 2003. Estimating the relative risk in cohort studies and clinical trials of common outcomes. Am J Epidemiol 157:940-3.

Miller KW, Wilder LB, Stillmn FA, Becker DM, 1997. The feasibility of a street-intercept survey method in an African-American community. Am J Public Health 87:655-8.

Mujahid MS, Diez-Roux AV, Cooper RC, Shea S, Williams DR, 2011. Neighborhood stressors and race/ethnic differences in hypertension prevalence (the Multi-Ethnic Study of Atherosclerosis). Am J Hypertens 24:187-93.

Mujahid MS, Diez-Roux AV, Morenoff JD, Raghunathan T, 2007. Assessing the measurement properties of neighborhood scales: from psychometrics to ecometrics. Am J Epidemiol 165:858-67.

Mujahid MS, Diez-Roux AV, Morenoff JD, Raghunathan TE, Cooper RS, Ni H, Shea S, 2008. Neighborhood characteristics and hypertension. Epidemiology 19:590-8.

Nguyen NT, Magno CP, Lane KT, Hinojosa MW, Lane JS, 2008. Association of hypertension, diabetes, dyslipidemia, and metabolic syndrome with obesity: findings from the National Health and Nutrition Examination Survey, 1999 to 2004. J Am Coll Surg 207:928-34.

Nwankwo T, Yoon S, Burt V, Gu Q, 2013. Hypertension among adults in the United States: National Health and Nutrition Examination Survey, 2011-2012. NCHS Data Brief 113:1-8.

Ogden CL, Carroll MD, Kit BK, Flegal KM, 2014. Prevalence of childhood and adult obesity in the United States, 2011-2012. J Am Med Assoc 311:806-14.

Ompad DC, Galea S, Marshall G, Fuller CM, Weiss L, Beard JR, Chan C, Edwards V, Vlahov D, 2008. Sampling and recruitment in multilevel studies among marginalized urban populations: the IMPACT studies. J Urban Health 85:268-80.

Ostchega Y, Hughes JP, Wright JD, McDowell MA, Louis T, 2008. Are demographic characteristics, health care access and utilization, and comorbid conditions associated with hypertension among US adults? Am J Hypertens 21:159-65.

Pham Do Q, Ommerborn MJ, Hickson DA, Taylor HA, Clark CR, 2014. Neighborhood safety and adipose tissue distribution in African Americans: the Jackson Heart Study. PLoS One 9:e105251.

Prushansky T, Geller S, Avraham A, Furman C, Sela L, 2013. Angular and linear spinal parameters associated with relaxed and erect postures in healthy subjects. Physiother Theory Pract 29:249-57.

Ravenell JE, Thompson H, Cole H, Plumhoff J, Cobb G, Afolabi L, Boutin-Foster C, Wells M, Scott M, Ogedegbe G, 2013. A novel community-based study to address disparities in hypertension and colorectal cancer: a study protocol for a randomized control trial. Trials 14:287. 
Reitzel LR, Regan SD, Nguyen N, Cromley EK, Strong LL, Wetter DW, McNeill LH, 2014. Density and proximity of fast food restaurants and body mass index among African Americans. Am J Public Health 104:110-6.

Rossen LM, Schoendorf KC, 2012. Measuring health disparities: trends in racial-ethnic and socioeconomic disparities in obesity among 2to 18-year old youth in the United States, 2001-2010. Ann Epidemiol 22:698-704.

Rundle A, Diez-Roux A, Freel L, Miller D, Necerkman K, Weiss C, 2007. The urban built environment and obesity in New York City: a multilevel analysis. Am J Health Promot 21:326-34.

Rundle A, Neckerman KM, Freeman L, Lovasi GS, Purciel M, Quinn J, Richards C, Sircar N, Weiss C, 2009. Neighborhood food environment and walkability predict obesity in New York City. Environ Health Persp 117:442-7.

Saelens BE, Sallis JF, Franks LD, Couch SC, Zhou C, Colburn T, Cain KL, Chapman J, Glanz K, 2012. Obesogenic neighborhood environments, child and parent obesity: the Neighborhood Impact on Kids Study. Am J Prev Med 42:e57-e64.

Sampson R, Raudenbush S, 2004. Seeing disorder: neighborhood stigma and the social construction of broken windows. Soc Psychol Quart 67:319-42.

Schmidt C0, Kohlmann T, 2008. When to use the odds ratio or the relative risk? Int J Public Health 53:165-7.

Schwartz BS, Stewart WF, Godby S, Pollak J, Dewalle J, Larson S, Mercer DG, Glass TA, 2011. Body mass index and the built and social environments in children and adolescents using electronic health records. Am J Prev Med 41:e17-e28.

Shulman GI, 2014. Ectopic fat in insulin resistance, dyslipidemia, and cardiometabolic disease. New Engl J Med 371:1131-41.

Stark JH, Neckerman K, Lovasi GS, Konty K, Quinn J, Arno P, Viola D, Harris TG, Weiss CC, Bader MD, Rundle A, 2013. Neighbourhood food environments and body mass index among New York City adults. J Epidemiol Community H 67:736-42.

Tabuchi T, Fukuhara H, Iso H, 2012. Geographically-based discrimination is a social determinant of mental health in a deprived or stigmatized area in Japan: a cross-sectional study. Soc Sci Med 75:1015-21.

Thomas E, Collins A, McCarthy J, Fitzpatrick J, Durighel G, Goldstone A, Bell J, 2010. Estimation of abdominal fat compartments by bioelectrical impedance: the validity of the ViScan measurement system in comparison with MRI. Eur J Clin Nutr 64:525-33.

Thompson L, Pearce J, Barnett J, 2007. Moralising geographies: stigma, smoking islands and responsible subjects. Area 39:508-17.
Thompson ML, Myers JE, Kriebel D, 1998. Prevalence odds ratio or prevalence ratio in the analysis of cross sectional data: what is to be done? Occup Environ Med 55:272-7.

Troped PJ, Starnes HA, Puett RC, Tamua K, Cromley EK, James P, BenJoseph E, Melly SJ, Laden F, 2014. Relationships between the built environment and walking and weight status among older women in three U.S. States. J Aging Phys Activ 22:114-25.

Troped PJ, Wilson JS, Matthews CE, Cromley EK, Melly SJ, 2010. The built environment and location-based physical activity. Am J Prev Med 38:429-38.

Unger E, Diez-Roux AV, Lloyd DM, Mujahid MS, Nettleton JA, Bertoni A, Badon SE, Ning H, Allen NB, 2014. Association of neighborhood characteristics with cardiovascular health in the Multi-Ethnic Study of Atherosclerosis. Circ Cardiovasc Qual Outcomes 7:524-31.

United States Census Bureau, 2010. American Community Survey. Available from: https://www.census.gov/programs-surveys/acs/

Victor RG, Ravenell JE, Freeman A, Leonard D, Bhat DG, Shafiq M, Knowles P, Storm JS, Adhikari E, Bibbins-Domingo K, 2011. Effectiveness of a barber-based intervention for improving hypertension control in black men: the BARBER-1 study: a cluster randomized trial. Arch Intern Med 171:342-50.

WHO, 2013. A global brief on hypertension. Available from: http://apps.who.int/iris/bitstream/10665/79059/1/WHO_DCO_WHD _2013.2_eng.pdf

Wiehe SE, Kwan MP, Wilson J, Fortenberry JD, 2013. Adolescent healthrisk behavior and community disorder. PLoS One 8:e77667.

Wilson WJ, 1996. When work disappears: the new world of the urban poor. Alfred Knopf, New York, NY, USA.

Yahia N, El-Ghazale H, Achkar A, Rizk S, 2011. Dieting practices and body image perception among Lebanese university students. Asia Pac J Clin Nutr 20:21.

Yan K, Tracie B, Marie-Eve M, Melanie H, Jean-Luc B, Benoit T, St-Onge M, Marie L, 2014. Innovation through wearable sensors to collect real-life data among pediatric patients with cardiometabolic risk factors. Int J Pediatr 2014:328076.

Yen IH, Leung CW, Lan M, Sarrafzadeh M, Kayekjian KC, Duru OK, 2015. A pilot study using global positioning systems (GPS) devices and surveys to ascertain older adults' travel patterns. J Appl Gerontol 34:190-201.

Zenk SN, Schulz AJ, Matthews SA, Odoms-Young A, Wilbur J, Wegrzyn L, Gibbs K, Braunschweig C, Stokes C, 2011. Activity space environment and dietary and physical activity behaviors: a pilot study. Health Place 17:1150-61. 